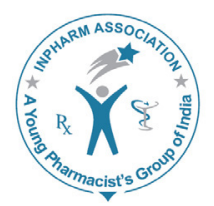

\title{
Colon Specific Drug Delivery: Effect of Eudragit Enteric Coating on Hydroxypropyl Methylcellulose Matrix Tablets of Flurbiprofen
}

\author{
Sateesh Kumar Vemula ${ }^{1,2^{*}}$ \\ ${ }^{1}$ Department of Pharmaceutics, Chaitanya College of Pharmacy Education and Research, Hanamkonda, \\ Warangal, Telangana, India. \\ ${ }^{2}$ Department of Pharmacy, College of Medical \& Health Sciences, Wollega University, Nekemte, P.Box No \\ 395. Ethiopia.
}

\begin{abstract}
Objective: The present research is focused on developing flurbiprofen colon-specific tablets based on timed release and $\mathrm{pH}$-sensitivity. Methods and Material: This study is designed to study the effect of eudragit coating on the drug release from hydroxypropyl methylcellulose matrix to achieve the colon-specific release. Hydroxypropyl methylcellulose matrix tablets were prepared by wet granulation method and coated with eudragit $\mathrm{S} 100$ using dip coating method. Then the tablets were evaluated for different physical parameters, compatibility studies, in vitro dissolution and in vivo x-ray imaging studies. Statistical Analysis: In the stability studies, paired t-test is employed to determine the significance of difference at 0.05 level. Results: Flurbiprofen colon-specific tablets have been characterized for weight variation, hardness, friability and drug content. Based on in vitro drug release, the formulation F6 showed the low amount of drug release $(18.41 \pm 0.68 \%)$ in the initial lag period followed $100.43 \pm 3.33 \%$ in $24 \mathrm{~h}$. Compatibility studies revealed that there was no interaction between drug and the polymers. Similarity index value was found as 95.01 , which is more than 50 indicates similarity between the dissolution profile before and after storage. In support of the dissolution studies, $x$-ray imaging studies revealed that tablets reached the colon without disintegrating in the upper gastro intestinal tract. Conclusion: From the above results, it is obvious that the developed flurbiprofen enteric coated matrix tablets are suitable for colonic delivery.
\end{abstract}

Key words: Dip coating, Lag period, pH-sensitive, Timed release, X-ray imaging study.

\section{INTRODUCTION}

Colon-specific drug delivery through the oral route has gained increased importance to treat local diseases in colon and to give potential delivery of drugs that are used to treat colonic disorders. ${ }^{1-2}$ Traditionally, colon targeting is achieved with approaches like prodrug, $\mathrm{pH}$-sensitivity,

\begin{tabular}{|l|l|}
\hline \multicolumn{2}{|c|}{ Access this article online } \\
\hline \multirow{2}{*}{ Journal Sponsor } & \\
\hline \multirow{2}{*}{ www.phcog net } & $\begin{array}{l}\text { Website: } \\
\text { www.jyoungpharm.org }\end{array}$ \\
\cline { 2 - 3 } & $\begin{array}{l}\text { DOI: } \\
\text { 10.5530/jyp.2015.4.12 }\end{array}$ \\
& \\
\hline
\end{tabular}

*Address for correspondence:

Dr. Sateesh Kumar Vemula, M. Pharm, PhD, Department of Pharmaceutics, Chaitanya College of Pharmacy Education and Research, Warangal,AP, India-506001.E-mail:vemulasatish15@gmail.com time-dependent and microbial degradation dependent approaches. ${ }^{3}$ Combination of any of the above two approaches has superior applicability in colon-specific delivery than any single approach. Combining timedependent and $\mathrm{pH}$-sensitive approaches can result in an optimum formulation with low polymer content, that can show negligible drug release in the initial stages but can release the drug completely and in a sustained fashion when the tablet reaches colon. ${ }^{4}$ Examples for such techniques include flurbiprofen compression coated tablets, ${ }^{5}$ flurbiprofen-sodium alginate compression coated tablets, ${ }^{6}$ meloxicam microsponges, ${ }^{7}$ diclofenac sodium compression coated tablets, ${ }^{8}$ ketorolac matrix tablets, ${ }^{9}$ flurbiprofen-guar 


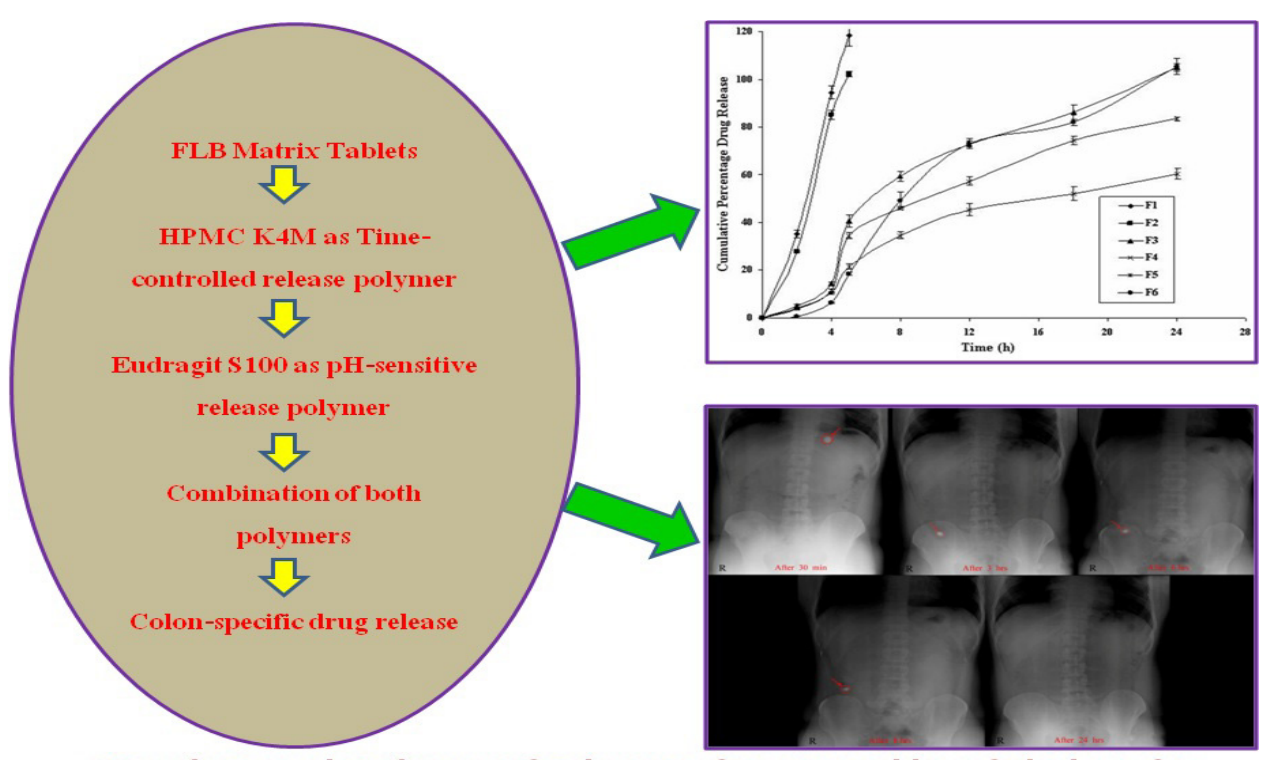

Formulation and Evaluation of Colon-specific Matrix tablets of Flurbiprofen

Graphical Abstract

gum tablets, ${ }^{10}$ indomethacin matrix tablets, ${ }^{4}$ time-dependent 5-fluorouracil tablets, ${ }^{11}$ flurbiprofen microsponges ${ }^{12}$ and time-dependent ketorolac compression coated tablets. ${ }^{13}$

Formulation of matrix tablets is inexpensive method and easy to manufacture with conventional tabletting facilities and few process variables. ${ }^{14}$ To achieve colonic drug delivery, preparation of matrix tablets is a simple method when compared to other methods. HPMC is a synthetic release retardant that is widely used as an extended release agent in the pharmaceutical industry. ${ }^{15}$ Eudragit S100 with a threshold $\mathrm{pH} 7$ was selected as the coating material for this study. Eudragit S100's coating integrity can withstand lower $\mathrm{pH}$ values of stomach and small intestine, but can dissolve at the neutral or alkaline $\mathrm{pH}$ of the terminal ileum. ${ }^{16-17}$ Flurbiprofen (FLB) is a non-steroidal anti-inflammatory drug used to treat inflammation and pain related to colon. ${ }^{18}$ The frequent intake of FLB leads to gastric ulceration, bleeding and other gastric complications. ${ }^{19}$ Hence the development of FLB colon specific tablets is appropriate to reduce its side effects and achieve high local drug concentrations in the colon. ${ }^{20}$ Thus the significant plan of present study is to develop FLB enteric coated HPMC matrix tablets for colon delivery by combining time dependent and $\mathrm{pH}$-sensitive approaches.

\section{MATERIALS AND METHODS}

\section{Materials}

Flurbiprofen was a gift sample from FDC Limited, Mumbai, India. Various grades of HPMC and Eudragit S100 were gift samples from Matrix laboratories, Hyderabad, India. All other chemicals used were of analytical grade.

\section{Powder characterization}

Evaluation of powder mixtures flow properties was done by measuring angle of repose, bulk density, tapped density and compressibility index. The fixed funnel method was employed to measure the angle of repose $(\theta)$ and it was calculated using the following formula:

$$
\operatorname{Tan} \theta=h / r
$$

In which, $\theta$ is the angle of repose, $h$ is the height of the cone and $r$ is radius of the cone base. To measure the angle of repose, a funnel was fixed to a stand so that the lower tip of the funnel is $2.5 \mathrm{~cm}$ above the surface. A graph paper was placed on a flat surface. The powder blend was allowed to fall freely on the graph paper through the funnel, till the tip of the heap formed just touches the funnel. The radius of the heap was noted and from this angle of repose was determined. Angle of repose less than $30^{\circ}$ suggests free flowing properties of the material.

The bulk density of a powder is calculated by measuring the volume of a known mass of powder sample that may have been passed through a screen, into a $50 \mathrm{ml}$ graduated cylinder. Tapped densities of powder samples were estimated by a tap density apparatus (Intelli, Kshitij Innovations, India). The apparatus was set for 500 tappings for $5 \mathrm{~min}$ at a stroke height of $20 \mathrm{~mm} .{ }^{5}$ The compressibility index (Carr's Index) was calculated from the bulk density 
$\left(\varrho_{\mathrm{b}}\right)$ and tapped density $\left(\varrho_{\text {tap }}\right)$ using the following formula:

$$
\text { Carr's Index } \left.=\left(\left(\varrho_{\text {tap }}-\varrho_{b}\right) / \varrho_{b}\right) / \times 100 \quad---2\right)
$$

\section{Preparation of matrix tablets}

Wet granulation method was adopted to prepare the HPMC matrix tablets. FLB, HPMC and excipients other than glidant and lubricant were accurately weighed, passed through 60 mesh sieves and mixed in a poly bag for 5-10 min, and then granules were prepared with the addition of $5 \%$ polyvinyl pyrrolidine in alcohol as binding agent, dried at $40^{\circ} \mathrm{C}$ for $15 \mathrm{~min}$ and sieved to obtain uniformly sized granules (18 mesh and 22 mesh sieves used for granulation and sieving of dried granules respectively). The obtained granules were lubricated with talc and magnesium stearate by blending for another $5 \mathrm{~min}$. The resultant mixture was directly compressed into tablets using $5000 \mathrm{~kg}$ compression pressure with $9 \mathrm{~mm}$ round flat punches using 16-station rotary tabletting machine (Cadmach, Ahmedabad, India). The final weight of the tablet was adjusted to $300 \mathrm{mg}$. The compositions of the matrix tablets were given in Table 1.

\section{Enteric coating}

The enteric coating solution was prepared by dissolving Eudragit S100 in acetone at 10\% w/v. Coating of optimized matrix formulation (F3), that showed poor release during the initial period of dissolution, was performed by dip coating method. Samples were taken, weighed, and the mean coat weight calculated. The process was repeated until the desired amount of coating per tablet was achieved.
The tablets were coated at different levels from about 5 to $30 \% \mathrm{w} / \mathrm{w}$ as total solid applied.

\section{Evaluation of physical parameters}

The designed formulations were studied for their physical properties like weight variation, hardness and friability. For estimating weight variation, 20 tablets of each formulation were weighed using an electronic weighing balance (AW 120, Shimadzu Corporation, Japan). The hardness of six tablets was measured using Monsanto tablet hardness tester. Friability was determined on ten tablets in a Roche friabilator (Electrolab, Mumbai, India).

\section{Determination of drug content by HPLC method}

For estimation of drug content, ten tablets were crushed, and $100 \mathrm{mg}$ of the powder was accurately weighed and transferred to a $100 \mathrm{ml}$ volumetric flask. Initially about 50 $\mathrm{ml}$ of mobile phase was added to the volumetric flask and allowed to stand for 6-8 $\mathrm{h}$ with intermittent shaking to ensure complete solubility of the drug. Then the volume was made up to $100 \mathrm{ml}$ with mobile phase followed by filtration and analysis for FLB content by the previously developed HPLC method. Mobile phase used for the analysis consists of phosphate buffer: acetonitrile aqueous solution in the ratio of 35:65. They were filtered before use through a $0.45 \mu \mathrm{m}$ membrane filter and pumped through the column Symmetry C18 (XTerra, 4.6 x $150 \mathrm{~mm}$ ) $5 \mu \mathrm{m}$, at a flow rate of $1 \mathrm{ml} / \mathrm{min}$. Prior to the injection of the drug solution, the column was equilibrated for at least 30 min with the mobile phase flowing through the system.

Table 1: Composition of FLB colon specific matrix tablets

\begin{tabular}{|ccccccc}
\hline $\begin{array}{c}\text { Ingredients } \\
\text { (Quantity in mg/tablet) }\end{array}$ & F1 & F2 & F3 & F4 & F5 & F6 \\
\hline Flurbiprofen & 100 & 100 & 100 & 100 & 100 & 100 \\
\hline HPMC E50 & 40 & - & - & - & - & - \\
HPMC E100 & - & 40 & - & - & - & - \\
\hline HPMC K4M & - & - & 40 & - & - & 40 \\
\hline HPMC K15M & - & - & - & 40 & - & - \\
\hline HPMC K100M & - & - & - & - & 40 & - \\
\hline Eudragit S100 & - & - & - & - & - & 60 \\
\hline $\begin{array}{c}\text { Spry dried Lactose } \\
\text { Sodium Lauryl }\end{array} \quad 148$ & 148 & 148 & 148 & 148 & 148 \\
\hline Sulphate & 3 & 3 & 3 & 3 & 3 & 3 \\
Talc & 6 & 6 & 6 & 6 & 6 & 6 \\
\hline Magnesium Stearate & 3 & 3 & 3 & 3 & 3 & 3 \\
\hline Total Weight & 300 & 300 & 300 & 300 & 300 & 360 \\
\hline
\end{tabular}


The analysis was performed at ambient temperature and the run time was set to $8 \mathrm{~min}$. The eluents were monitored at $254 \mathrm{~nm}$ using UV detector. ${ }^{5}$

\section{In vitro dissolution study}

The release of FLB from tablets was carried out using USP XXIV Type I dissolution apparatus (Electro lab, TDT08L) at a rotation speed of $50 \mathrm{rpm}$, and a temperature of $37 \pm 0.5^{\circ} \mathrm{C}$. In order to simulate the gastrointestinal transit conditions, the tablets were subjected to different dissolution media. Initially, the drug release was carried out for $2 \mathrm{~h}$ in $0.1 \mathrm{~N} \mathrm{HCl}, 2 \mathrm{~h}$ in buffer $\mathrm{pH} 5.5$ and finally in phosphate buffer $\mathrm{pH} 7.4$ up to $24 \mathrm{~h}$. At specific time intervals, $5 \mathrm{ml}$ samples were withdrawn and replaced by an equal volume of fresh pre-warmed dissolution medium. The samples were filtered through $0.45 \mu \mathrm{m}$ membrane filter (Millipore, USA) and analyzed at $254 \mathrm{~nm}$ using UV detector by HPLC method.

\section{In vitro release kinetics}

The data obtained from the in vitro dissolution studies was fitted to zero order, first order and Higuchi models to explain the pattern and the release mechanism from the formulations. Koresmeyer-Peppas model is one of the mathematical expressions, used to understand the mechanism of drug release from these formulations. ${ }^{21}$ The mean dissolution time (MDT) is defined as the sum of different release fraction periods (release areas) during dissolution studies divided by the initial loading dose. ${ }^{22}$ $\mathrm{T} 10 \%$ and $\mathrm{T} 80 \%$ (time in hours to take $10 \%$ and $80 \%$ drug release, respectively) were calculated to clarify the colon-specific release from matrix tablets. ${ }^{13}$

\section{Drug-polymer interaction studies}

To study the possible interaction between FLB and HPMC, DSC study was carried out on pure drug and optimized formulation (F6) and the thermograms were obtained using DSC (Perkin-Elmer, Shelton, U.S). The analyses were performed under nitrogen (nitrogen flow rate $50 \mathrm{ml} / \mathrm{min}$ ) in order to eliminate oxidative and pyrrolytic effects at a standard heating rate of $15^{\circ} \mathrm{C} / \mathrm{min}$ over a temperature range of $(50-350)^{\circ} \mathrm{C}$. The FTIR spectra of FLB and optimized formulation (F6) recorded between 400 to 4000 $\mathrm{cm}^{-1}$ on FTIR to detect the drug-excipient interactions. The FTIR spectra for the test samples were obtained using $\mathrm{KBr}$ disk method using an FTIR spectrometer (Perkin Elmer FTIR, Perkin Elmer Inst. USA). The resultant spectra were compared for any possible changes in the peaks of the spectra.

\section{Stability studies}

Stability studies were carried out according to ICH guidelines to assess the drug and formulation stability. Optimized formulation F6 was sealed in aluminum packaging coated inside with polyethylene, and three replicates were kept in the humidity chamber maintained at $40 \pm 2^{\circ} \mathrm{C}$ and $75 \pm 5 \% \mathrm{RH}$ for six months. ${ }^{23-24}$ Samples were collected after six months of storage and analyzed for the drug content and in vitro dissolution rate ${ }^{25}$ and they were subjected to statistical analysis using paired $t$-test to test the significance of difference at 0.05 level of significance (LS). Then the similarity index was calculated between dissolution rates of optimized tablets before and after storage to prove the stability of the dosage form. The similarity factor $\left(\mathrm{F}_{2}\right)$ is a logarithmic reciprocal square root transformation of the sum of squared error and is a measurement of the similarity in the percent $(\%)$ of dissolution between the two curves.

$$
F_{2}=50 \times \log \left\{\left[1+(1 / n) \sum_{t=1} n\left(R_{t}-T\right) 2\right]-0.5 \times 100\right\}
$$

\section{In vivo $x$-ray imaging studies}

X-ray imaging technique was used to monitor tablets throughout the GI system. The inclusion of radioopaque material into the solid dosage form enables it to be visualized by the use of $\mathrm{x}$-rays. By incorporating barium sulphate $(20 \mathrm{mg})$ into the pharmaceutical dosage forms, it is possible to follow the movement, location and integrity of the dosage form after oral administration by placing the subject under a fluoroscope and taking a series of $x$-ray films at various time points. Three healthy male human volunteers, between 22-30 years of age and 50-70 kg body weight, were participated in x-ray imaging studies. They were non-alcoholics, non-smokers and have not taken any drugs. The purpose of the study was fully explained to the volunteers and the volunteers had given their written consent. Each subject ingested barium sulphate containing optimized formulation (F6) orally with $200 \mathrm{ml}$ water, after an overnight fast. The tablets were visualized using films exposed to $\mathrm{x}$-rays. Abdominal radiographs were taken after $30 \mathrm{~min}, 3 \mathrm{~h}, 6 \mathrm{~h}, 8 \mathrm{~h}$ and $24 \mathrm{~h}$ in all the subjects. The volunteers were served with food; $2 \mathrm{~h}$ (breakfast) and $4 \mathrm{~h}$ (lunch) after the administration of the tablet. ${ }^{26}$ The institutional ethical committee (Approval No. 338-03/JIPS/JNG/IHEC/2011) approved the protocol of the $\mathrm{x}$-ray imaging study of colon targeted tablets of FLB. 
Table 2: Characterization of powder mixture

\begin{tabular}{|ccccc|} 
Formulation & $\begin{array}{c}\text { Angle of } \\
\text { Repose* }^{*}(\mathbf{0})\end{array}$ & $\begin{array}{c}\text { Bulk } \\
\text { Density }(\mathbf{g} / \mathbf{c c})\end{array}$ & $\begin{array}{c}\text { Tapped } \\
\text { Density }(\mathbf{g} / \mathbf{c c})\end{array}$ & $\begin{array}{c}\text { Carr's } \\
\text { Index (\%) }\end{array}$ \\
\hline F1 & $31.45 \pm 0.98$ & 0.336 & 0.392 & 16.67 \\
\hline F2 & $29.83 \pm 4.04$ & 0.322 & 0.383 & 18.94 \\
\hline F3 & $31.13 \pm 0.93$ & 0.324 & 0.387 & 16.28 \\
\hline F4 & $28.90 \pm 1.24$ & 0.332 & 0.394 & 18.67 \\
\hline F5 & $30.14 \pm 3.50$ & 0.334 & 0.397 & 18.86 \\
\hline F6 & $30.42 \pm 3.76$ & 0.327 & 0.389 & 15.94 \\
\hline
\end{tabular}

*All Values Represent Mean \pm Standard Deviation, $n=3$

Table 3: Physical properties of FLB colon specific matrix tablets

\begin{tabular}{ccccc|} 
Formulation & $\begin{array}{c}\text { Weight } \\
\text { variation* }\end{array}$ & $\begin{array}{c}\text { Hardness } \\
(\mathbf{K g})\end{array}$ & $\begin{array}{c}\text { Friability } \\
(\mathbf{K g m})\end{array}$ & $\begin{array}{c}\text { Drug content } \\
(\%)\end{array}$ \\
\hline F1 & $300.45 \pm 3.49$ & $6.23 \pm 0.46$ & 0.22 & $99.73 \pm 0.58$ \\
\hline F2 & $300.20 \pm 3.83$ & $6.07 \pm 0.29$ & 0.50 & $98.69 \pm 1.12$ \\
\hline F3 & $299.34 \pm 3.79$ & $6.03 \pm 0.31$ & 0.39 & $99.86 \pm 0.71$ \\
\hline F4 & $299.75 \pm 3.99$ & $6.20 \pm 0.36$ & 0.39 & $98.92 \pm 1.45$ \\
\hline F5 & $301.05 \pm 4.03$ & $6.40 \pm 0.10$ & 0.44 & $99.24 \pm 1.01$ \\
\hline F6 & $361.56 \pm 3.12$ & $6.03 \pm 0.31$ & 0.39 & $99.97 \pm 2.20$ \\
\hline
\end{tabular}

All values represent mean \pm standard deviation, ${ }^{*} n=20 ; \nmid n=6: \ddagger n=3$.

\section{RESULTS}

\section{Powder characterization}

The powder mixtures of different formulations were evaluated for angle of repose, bulk density (apparent and tapped), compressibility index and their values were shown in Table 2 . The apparent and tapped bulk density values ranged from 0.322 to 0.336 and 0.383 to 0.397 respectively. The results of angle of repose and \% Carr's index ranged from $28.90 \pm 1.24$ to $31.45 \pm 0.98$ and 15.94 to 18.94 respectively.

\section{Evaluation of physical parameters}

The physical properties of FLB-HPMC matrix tablets were given in Table 3 . In weight variation test, the pharmacopoeial limit for the tablets is not more than $5 \%$ of the average weight and found to be $299.34 \pm 3.79-361.56 \pm 3.12$. The hardness of the tablets was found to be in the range of 6.03 \pm 0.31 to $6.40 \pm 0.10 \mathrm{~kg} / \mathrm{cm}^{2}$. Another measure of tablets strength is friability. Conventional compressed tablets that lose less than $1 \%$ of their weight are generally considered acceptable. The percentage friability for all formulations was below $1 \%$ i.e. $0.22-0.50 \%$, indicating that the friability is within the prescribed limits. The tablets were found to contain $98.69 \pm 1.12-99.97 \pm 2.20 \%$ of the labeled amount indicating uniformity of drug content.

\section{Effect of HPMC amount on matrix integrity}

From the cumulative mean percent of FLB released from matrix tablets containing varying amounts of HPMC K4M, incorporation of $40 \mathrm{mg}$ of polymer in the total tablet weight was found to be satisfactory to formulate a tablet with good integrity (data not presented).

\section{Effect of HPMC viscosity grade on matrix integrity}

Figure 1 showed the release profiles of FLB from the HPMC matrix tablets of different viscosity grades (F1F5). The cumulative mean percent of FLB released from above formulations was found to vary from $21.52 \pm 1.05$ to $102.22 \pm 1.18$ after $5 \mathrm{~h}$ of testing in simulated gastric and intestinal fluids and the percent drug release was increased gradually after $5 \mathrm{~h}$ and it was found to be $60.40 \pm 2.36$ to $100.43 \pm 3.33$ in $24 \mathrm{~h}$.

\section{Effect of Eudragit S100 coating}

In order to evaluate the effect of the coating level, release profile under $\mathrm{pH}$-gradient, formulation F3 tablets were coated with Eudragit S100 in amounts varying from 5 to 


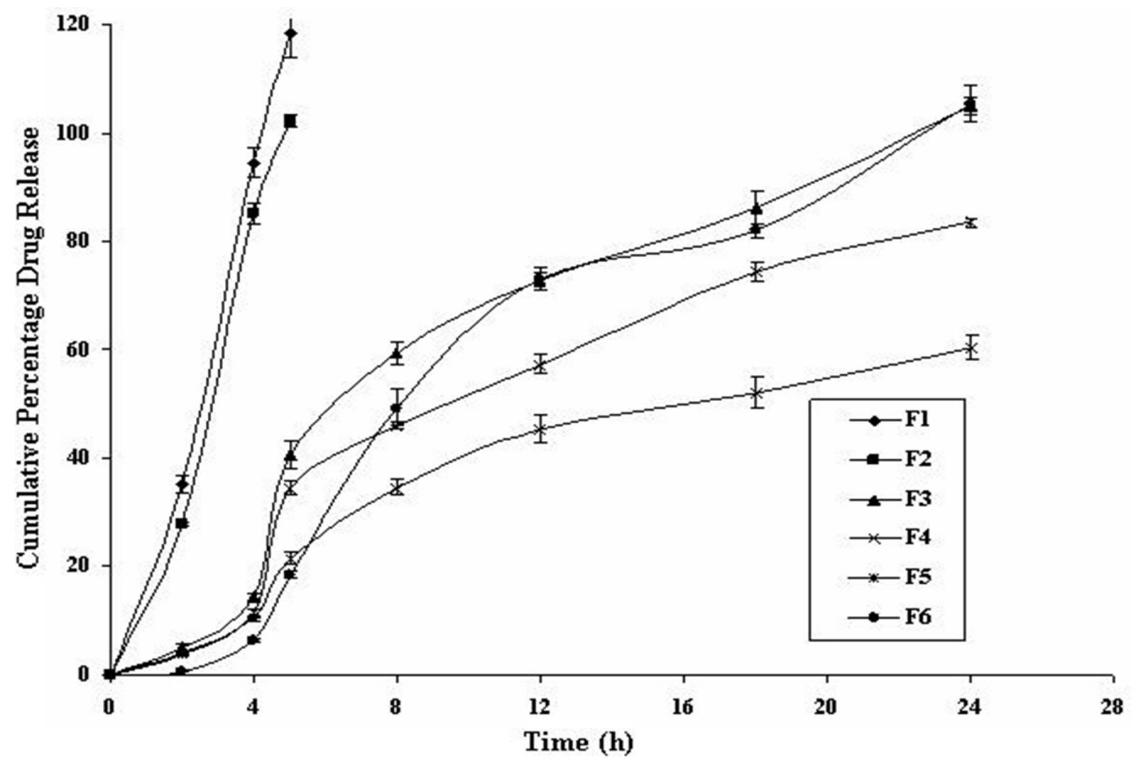

Figure 1: Release profile of FLB from uncoated and eudragit S100 coated HPMC matrix tablets

Table 4: Release kinetics of FLB colon specific matrix tablets

\begin{tabular}{ccccccc} 
Formulation & \multicolumn{2}{c}{ Zero Order } & \multicolumn{2}{c}{ First Order } & \multicolumn{2}{c}{ Higuchi } \\
\hline F1 & $\begin{array}{c}\mathbf{K}_{0} \\
(\mathbf{m g} / \mathbf{h r})\end{array}$ & $\mathbf{R}^{2}$ & $\begin{array}{c}\mathbf{K}_{\mathbf{1}} \\
\left(\mathbf{h r} \mathbf{r}^{-1}\right)\end{array}$ & $\mathbf{R}^{2}$ & $\begin{array}{c}\mathbf{K} \\
\left(\mathbf{m g} / \mathbf{h r}^{-1 / 2}\right)\end{array}$ & $\mathbf{R}^{2}$ \\
\hline F2 & 24.29 & 0.988 & 0.93272 & 0.875 & 50.74 & 0.881 \\
\hline F3 & 21.4 & 0.978 & 0.91199 & 0.891 & 34.49 & 0.865 \\
\hline F4 & 4.499 & 0.915 & 0.1543 & 0.627 & 23.86 & 0.922 \\
\hline F5 & 3.666 & 0.917 & 0.152 & 0.641 & 19.43 & 0.923 \\
\hline F6 & 2.635 & 0.914 & 0.14048 & 0.655 & 14.04 & 0.93 \\
\hline
\end{tabular}

$\mathrm{K}_{0}$-Zero order rate constant, $\mathrm{K}_{1}$-First order rate constant, $\mathrm{K}$-Higuchi model rate constant and $\mathrm{R}^{2}$-Correlation coefficient.

$30 \% \mathrm{w} / \mathrm{w}(\mathrm{F} 6)$. Figure 1 showed the comparison of release profiles of FLB from the enteric coated tablet to uncoated tablet. The cumulative mean percent of FLB released from above coated tablets was found to vary from $18.41 \pm 0.68$ after $5 \mathrm{~h}$ of testing in simulated gastric and intestinal fluids and the percent drug release was increased gradually after $5 \mathrm{~h}$ and it was found to be complete drug release (100.43 $\pm 3.33 \%)$ in $24 \mathrm{~h}$.

\section{In vitro release kinetics}

The values of $\mathrm{K}$, and $\mathrm{r}^{2}$ (correlation coefficient of the regression analysis) of zero order, first order and Higuchi models of designed formulations were given in Table 4 . The $\mathrm{n}$ values calculated for different formulations were found in the range of 1.2966 to 2.8776 . The MDT values were found to be $2.71-12.21$. The T10\% and T $80 \%$ values of optimized formulation was found to be $4.5 \mathrm{~h}$ and 17.9 $\mathrm{h}$ respectively. All these results were given in Table 5.

\section{Drug-polymer interaction studies}

DSC studies were performed to understand the nature of the drug in the formulated tablets. DSC curves obtained for pure drug and optimized formulation were showed in Figure 2. A sharp endothermic peak corresponding to the melting point of $\mathrm{FLB}$ was found at $116^{\circ} \mathrm{C}$. An endothermic peak corresponding to the melting point of FLB in optimized formulation was observed at $115.4^{\circ} \mathrm{C}$. The FTIR spectral analysis of pure FLB and optimized formulation were showed the principal peaks at similar wave numbers (Figure 3). The FTIR spectral analysis of FLB alone showed that the principal peaks were observed at wave numbers of $1701.22,1415.75,1217.06,923.9,765.7$ and $696.23 \mathrm{~cm}^{-1}$. In 
Table 5: Release kinetics of FLB colon specific matrix tablets

\begin{tabular}{|c|c|c|c|c|c|c|}
\hline Formulation & $\mathbf{K}$ & $\mathbf{n}$ & $\mathbf{R}^{2}$ & MDT (h) & $\mathrm{T} 10 \%(\mathrm{~h})$ & T80\% (h) \\
\hline F1 & 1.7645 & 2.8776 & 0.897 & 2.71 & 0.28 & 3.1 \\
\hline F2 & 1.6519 & 2.8171 & 0.914 & 2.70 & 0.42 & 3.9 \\
\hline F3 & 1.8217 & 1.4433 & 0.915 & 9.57 & 2.4 & 16.5 \\
\hline F4 & 1.6592 & 1.3592 & 0.921 & 9.16 & 3.9 & 23.8 \\
\hline F5 & 1.5617 & 1.2966 & 0.936 & 8.98 & 4.0 & 27.4 \\
\hline F6 & 1.5289 & 1.7495 & 0.905 & 12.21 & 4.5 & 17.9 \\
\hline
\end{tabular}

K-Kinetic rate constant, $\mathrm{n}$-diffusional exponent, $\mathrm{r}^{2}$-Correlation coefficient, MDT-Mean dissolution time, T10\%-Time to release $10 \%$ drug release and T80\%-Time to release $80 \%$ drug release.

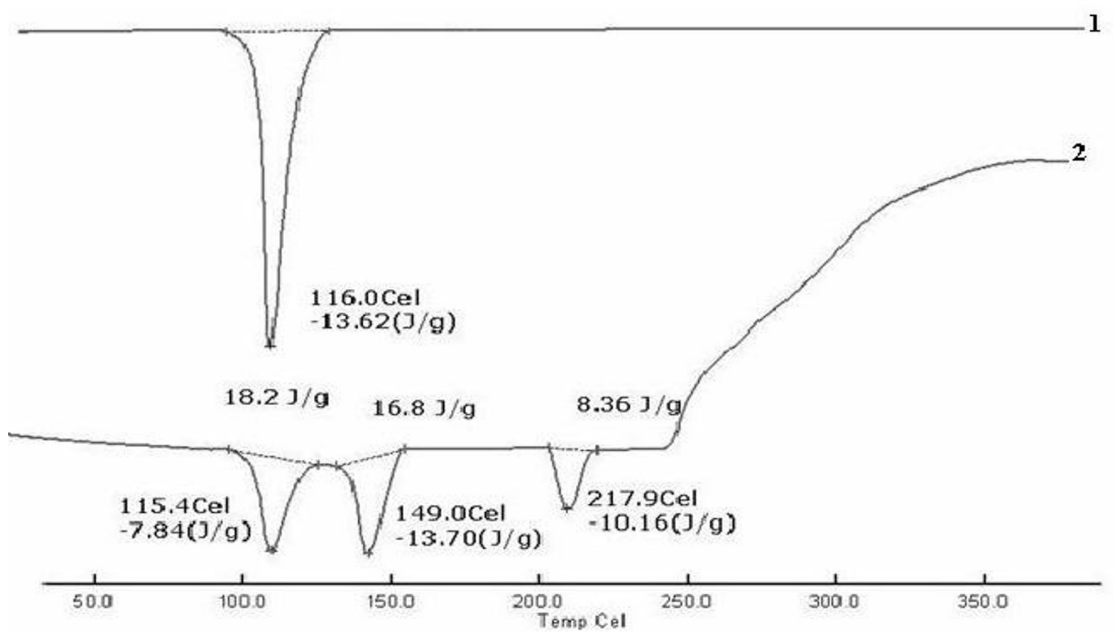

Figure 2: DSC thermograms of 1) FLB 2) F6 tablets

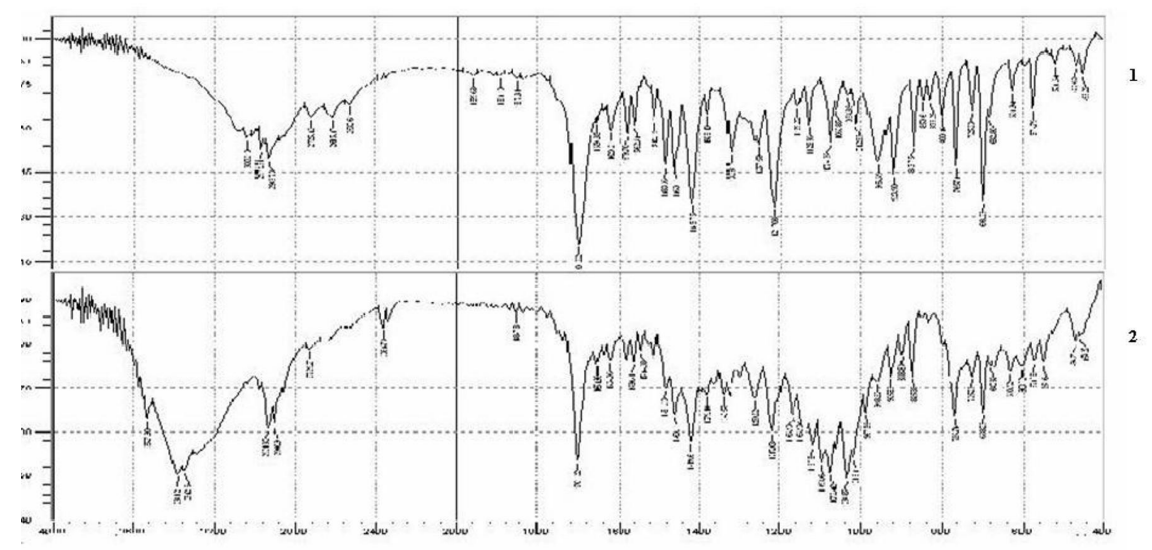

Figure 3: Fourier transform infrared spectra of 1) FLB 2) F6 tablets

the FTIR spectra of the optimized formulation (F6) were 1701.22, 1419.61, 1217.06, 925.83, 765.7 and $696.23 \mathrm{~cm}^{-1}$ wave numbers were observed. However, some additional peaks were observed with physical mixtures, which could be due to the presence of polymers.

\section{Stability studies}

In view of the potential utility of the formulation, stability studies were carried out at $40 \pm 2^{\circ} \mathrm{C}$ and $75 \pm 5 \% \mathrm{RH}$ for six months to assess their stability. After storage of six months, 


\begin{tabular}{|c|c|c|c|c|}
\hline Time (h) & Before storage & After 6 months & \multirow[t]{4}{*}{ Paired t-test } & $\begin{array}{l}\text { Similarity } \\
\text { Factor }\end{array}$ \\
\hline 0 & $0.00 \pm 0.00$ & $0.00 \pm 0.00$ & & \multirow{8}{*}{95.01} \\
\hline 2 & $0.71 \pm 0.15$ & $0.62 \pm 0.17$ & & \\
\hline 4 & $6.26 \pm 0.33$ & $6.14 \pm 0.41$ & & \\
\hline 5 & $18.41 \pm 0.68$ & $18.04 \pm 0.47$ & \multirow{5}{*}{$\begin{array}{c}\text { Not Significant at } \\
\text { 0.05LS }\end{array}$} & \\
\hline 8 & $49.23 \pm 3.30$ & $49.28 \pm 3.40$ & & \\
\hline 12 & $73.16 \pm 2.13$ & $72.36 \pm 0.93$ & & \\
\hline 18 & $82.10 \pm 1.33$ & $81.41 \pm 1.37$ & & \\
\hline 24 & $100.43 \pm 3.33$ & $99.40 \pm 1.92$ & & \\
\hline$\%$ Assay & $99.97 \pm 2.20$ & $99.12 \pm 1.57$ & $\begin{array}{c}\text { Not Significant at } \\
0.05 \mathrm{LS}\end{array}$ & -- \\
\hline
\end{tabular}

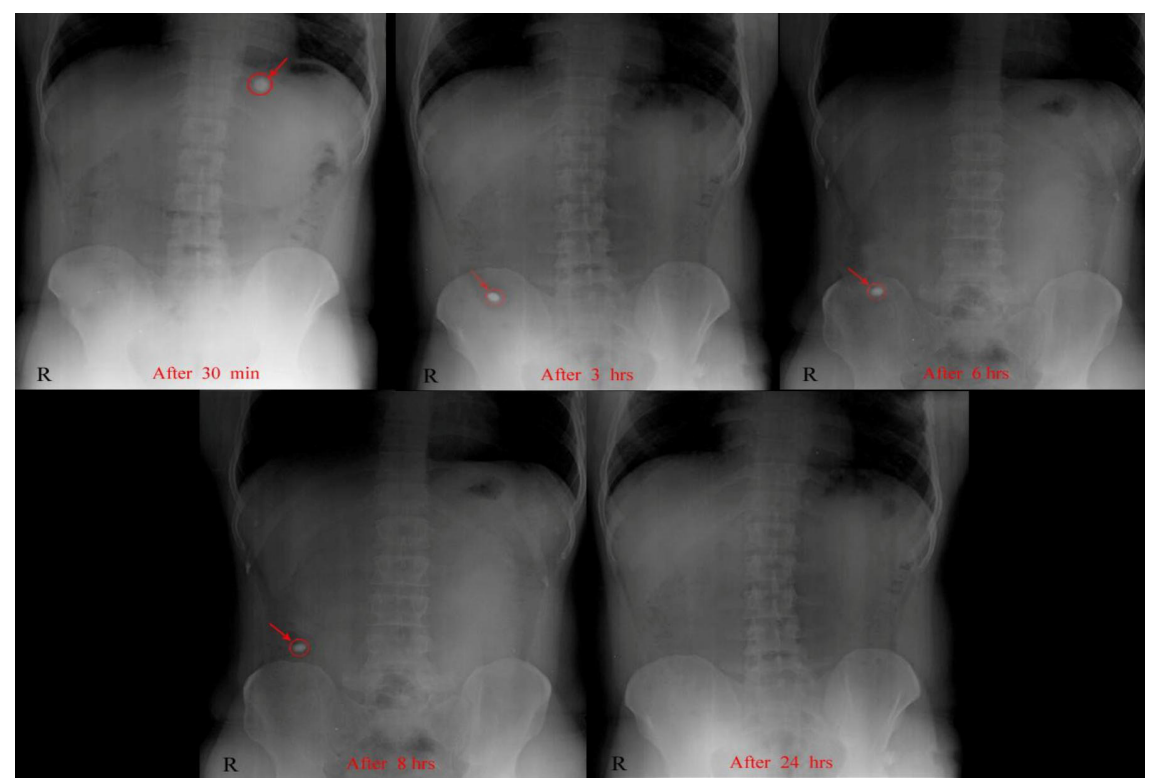

Figure 4: Positions of the FLB colon specific eudragit coated HPMC matrix tablets throughout the GI tract at different time points

the formulation was subjected to a drug assay and In vitro dissolution studies (Table 6 ) and from the statistical analysis there was no significant difference between before and after storage $(P<0.05)$. The similarity index value between dissolution profiles of optimized formulation before and after storage was found to be 95.01 .

\section{In vivo $\mathrm{x}$-ray imaging studies}

$\mathrm{X}$-ray studies were carried out on the F6 formulation tablets, in order to see the coated tablets throughout the GI system. Barium sulphate was used as the marker. The position of the tablets in the body was monitored at different time points. The abdominal radiographs showed that, the tablets remained intact in the stomach in all subjects. The transit time of the tablets throughout the GI system was variable.
The position of tablets at different time points is shown in the x-ray images of tablet throughout the GI system (Figure 4). From the abdominal radiographs, taken at different time points, the tablets entered the colon, varying between 3-6 $\mathrm{h}$ for all volunteers after tablet administration. These results are in agreement with the results of Ashford $e t$ al. who observed that the gastric emptying times of 0.6-2.9 h, small intestinal transit times of $1.8-8.5 \mathrm{~h}$ and colonic arrival time of 3.2-9.8 h while evaluating pectin as a compression coat for colonic delivery, using gamma scintigraphy. ${ }^{27}$

\section{DISCUSSION}

The angle of repose and \% Carr's index were measured to determine the flow properties of powder mixtures of all formulations and the results of angle of repose $(<35)$ 
and compressibility index $(<23)$ indicates fair to passable flow properties of the powder mixture. Appreciable flow properties facilitate the flow of powder mixture during the tabletting process. In a study reported in the literature i.e., Ketorolac tromethamine-HPMC matrix tablets, similar type of results were observed.?

The physical properties like weight variation, thickness, hardness and friability of all formulations were in compliance with pharmacopoeial standards, so all the tablets were with acceptable physical characteristics. In weight variation test, the pharmacopoeial limit for the tablets is not more than $5 \%$ of the average weight. The average percentage deviation of all tablet formulations was found to be within the above mentioned limit and hence all formulations passed the uniformity of weight as per official requirements of Indian Pharmacopoeia, 1996. From the physical characterization of all tablet formulations, it was found that they were uniform in hardness, friability and drug content. The hardness and friability are measure of tablets strength and integrity.

From the preliminary studies to optimize the polymer content in the tablet, different formulations were prepared and evaluated for drug release using the HPMC K4M. From the dissolution studies, the formulation containing $40 \mathrm{mg}$ of HPMC showed good drug release pattern in a controlled manner for $24 \mathrm{~h}$ with good physical properties and matrix integrity (data not presented). Dissolution study of F1-F5 formulations showed the effect of different viscosity grades of HPMC on release profiles of FLB from the HPMC matrix tablets. Formulations with HPMC of high viscosity formed swollen gel matrix with substantial integrity and the drug release was in a controlled manner which could be due to the better control of water and drug diffusion. Similar type of results observed in the reported studies of literature. ${ }^{4,11}$ On the contrary low viscosity grades of HPMC tablet lacked strength and were eroded quickly after swelling. In the present investigation, HPMC K4M in comparison to HPMC K15M and HPMC 100M showed negligible drug release in the initial lag period and followed by controlled release for $24 \mathrm{~h}$, which is the normal residence time of solid dosage form in the GIT. ${ }^{28}$ Thus the formulation F3 with HPMC K4M was considered better among other formulations to produce colon specific drug delivery of FLB and it is further improved by Eudragit S100 polymeric coating. The drug delivery systems targeted to the colon should not only protect the drug from being released in the physiological environment of stomach and small intestine, but also release the drug in colon. ${ }^{29}$
Eudragit S100, a methylacrylic acid-methylmethacrylate copolymer, was selected as the enteric coated polymer. It has about 30\% methacrylic acid units which tend to dissolve at $\mathrm{pH} 7$, and therefore, it is considered a suitable coating material for colonic drug delivery, to overcome the lower gastric and small intestine $\mathrm{pH}$ values. ${ }^{3}$ From the dissolution studies in different $\mathrm{pH}$ media, a progressive lag time increase and drug release rate decrease was observed with increasing the coating amount (data not presented). Study report on diclofenac sodium compression coated tablets also showed retardation of drug release as the Eudragit S100 percentage is increased in the compression coat. ${ }^{8}$ From the in vitro dissolution study the lowest coating level to obtain a lag time $(5 \mathrm{~h})$ considered suitable for achieving colonic targeting was found at $20 \% \mathrm{w} / \mathrm{w}$ of polymeric coat (F6). As a consequence of the progressive dissolution of the coating, the matrix tablets take up water rapidly and swelling occurs immediately, leading to the formation of a gel barrier through which the drug can diffuse.

The drug release kinetics studies revealed high correlation coefficient values for zero order than first order indicating that the drug release from matrix tablets followed zero order profile. Zero order release was also observed in a study with 5-fluorouracil using HPMC in the compression coat. ${ }^{11}$ The high regression value of Higuchi model ensured that the release of drug from matrix tablets followed diffusion mechanism. The $\mathrm{n}$ values calculated for different formulations indicate a supercase-II transport. The MDT was higher for formulations with high viscosity HPMC grades compared to low viscosity grades of HPMC, indicating better controlled release. Literature report on flurbiprofen compression coated tablets also showed similar type of results. ${ }^{5}$ Time in hours to take $10 \%$ and $80 \%$ drug release (T10\% and T80\%) explained the ability of colon specific release from matrix tablets that signifies the low amount of drug release in lag period and progressive release in colon.

DSC studies were performed to understand the nature of the drug in the formulated tablets. Thermogram of the optimized formulation did not show any significant shift in the endothermic peak when compared to pure drug, indicating that there was no change in FLB in the HPMC matrices. From the FTIR spectral analysis all the principal peaks observed in pure drug were present in the FTIR spectra of the optimized formulation (F6) and some additional peaks were observed with physical mixtures, which could be due to the presence of polymers. These results suggest that there is no interaction between the drug and polymers used in the present study. 
Table 7: FLB colon specific eudragit coated HPMC matrix tablets position throughout the GI tract at different time points

\begin{tabular}{|cccccc|}
\hline Time & $\mathbf{3 0 ~} \mathbf{m i n}$ & $\mathbf{3 h}$ & $\mathbf{6 h}$ & $\mathbf{8 h}$ & $\mathbf{2 4 h}$ \\
$\begin{array}{c}\text { Tablet } \\
\text { position }\end{array}$ & Stomach & Cecum & $\begin{array}{c}\text { Ascending } \\
\text { colon }\end{array}$ & $\begin{array}{c}\text { Ascending } \\
\text { colon }\end{array}$ & Notobserved \\
\hline
\end{tabular}

After storage of six months, the formulation was subjected to a drug assay and in vitro dissolution studies and the data showed that there was no significant change in formulation in the sense of drug content and dissolution behavior. The similarity index value was found as 95.01 , which is more than 50 indicates similarity between the dissolution profile before and after storage. ${ }^{30-31}$ The in vivo $\mathrm{x}$-ray imaging results showed that the tablets (F6) reached the colon without disintegrating in the upper region of the GI system in all subjects. The x-ray images showed that the tablets slowly disintegrated throughout the colon after reaching it. Colon targeted drug delivery systems have been visualized widely using gamma scintigraphy in the literature where the tablet integrity is lost in the colon. ${ }^{32}$ In the present study x-ray imaging studies showed gradual reduction in the size of the tablet with time until it disappeared completely (Table 7).

\section{CONCLUSION}

The present investigation was carried out with significant plan to develop FLB colon specific tablets. Time- $\mathrm{pH}-$ specific matrix tablets using HPMC and eudragit were decreased the drug release in the upper region of GIT, but gave good amount of drug release in colon. Based on in vitro drug release studies, F6 formulation (FLB: HPMC K4M: Eudragit S100 ratio of 1: 0.4: 0.6) showed the significant level of drug release in the colon with negligible loss in stomach and small intestine. From the drug release kinetics, above formulation followed zero order profile and the mechanism of drug release followed supercase II transport. Drug-excipients interaction studies and accelerated stability studies proved the stability of formulation. The in vivo $\mathrm{x}$-ray imaging study in human volunteers proved that the tablets (F6) reached the colon without disintegrating in the upper GIT. All in all, development of Eudragit S100 coated HPMC matrix tablets using combination of $\mathrm{pH}$-sensitive and time dependent approaches is a great methodology for colon specific delivery of flurbiprofen.

\section{ACKNOWLEDGEMENTS}

The authors acknowledge FDC Limited, Mumbai, India and Matrix laboratories, Hyderabad, India for gift sample of Flurbiprofen, HPMC K4M, and Eudragit S100. The authors also thank Principal and Management, Jangaon Institute of Pharmaceutical Sciences for providing facilities.

\section{ABBREVIATION}

HPMC: Hydroxypropyl methylcellulose

FLB: $\quad$ Flurbiprofen

DSC: Differential Scanning Calorimetry

FTIR: $\quad$ Fourier transform infrared spectra

\section{Highlights of Paper}

- Combination of time and $\mathrm{pH}$-dependent approaches is able to gain the colon-specific drug release.

- F6 formulation (FLB: HPMC K4M: Eudragit S100 ratio of 1: 0.4: 0.6) showed the significant level of drug release in the colon (100.43 $\pm 3.33 \%)$ with negligible loss in stomach and small intestine $(18.41 \pm 0.68 \%)$.

- The T10\% and T80\% values of F6 formulation was found to be $4.5 \mathrm{~h}$ and $17.9 \mathrm{~h}$.

- The similarity factor value between dissolution profiles of F6 formulation before and after storage was found to be 95.01 .

\section{Author Profile}

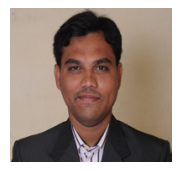

- Dr. Sateesh Kumar Vemula: Is an accomplished researcher, eminent teacher in Pharmaceutical Sciences. Presently working as Associate Professor in Department of Pharmacy, College of Medical \& Health Sciences, Wollega University, Ethiopia. He has 9 yrs teaching experience and an extensive research experience in Colonspecific drug delivery systems, Fast dissolving tablets, Solid dispersions, and Liquisolid tablets. He has more than 45 research publications in several international and national journals, 20 poster/oral presentations as presenting author in several national and international conferences and guided $18 \mathrm{M}$. Pharm students. 


\section{REFERENCES}

1. Vemula SK, Veerareddy PR. Different approaches to design and evaluation of colon specific drug delivery systems. Int J Pharm Tech. 2009; 1(1): 1-35.

2. Maroni A, Zema L, Curto MDD, Foppoli A, Gazzaniga A. Oral colon delivery of insulin with the aid of functional adjuvants. Adv Drug Del Rev. 2012; 64(6): 540-6.

3. Vincent HL, Suman KM. Drug delivery-oral colon-specific. In: Swarbick J, Boylan CJ, editors. Encyclopedia of Pharmaceutical Technology. New York: Marcel Dekker Inc; 2002. p. 871-85.

4. Asghar LF, Chure CB, Chandran S. Colon specific delivery of indomethacin: Effect of incorporating $\mathrm{pH}$ sensitive polymers in xanthan gum compression coated bases. AAPS Pharm Sci Tech. 2009; 10(2): 418-29.

5. Veerareddy PR, Vemula SK. Formulation, evaluation and pharmacokinetics of colon targeted pulsatile system of flurbiprofen. J Drug Targ. 2012; 20(08): 703-14.

6. Makhlof A, Tozuka Y, Takeuchi H. pH-sensitive nanospheres for colon-specific drug delivery in experimentally induced colitis rat model. Eur J Pharm Biopharm. 2009; 72(1): 1-8.

7. Srivastava R, Kumar D, Pathak K. Colonic luminal surface retention of meloxicam microsponges delivered by erosion based colon-targeted matrix tablet. Int J Pharm. 2012; 427(2): 153-62.

8. Chickpetty SM, Baswaraj R, Nanjwade BK. Studies on development of novel combined time and $\mathrm{pH}$ dependent solventless compression coated delivery systems for colonic delivery of diclofenac sodium. Asian J Pharm Clin Res. 2010; 3(2): 110-13.

9. Vemula SK, Veerareddy PR. Formulation and evaluation of ketorolac tromethamine tablets for time and $\mathrm{pH}$ dependent colon specific delivery. J Cur Pharm Res. 2011; 8(1): 31-9.

10. Vemula SK, Bontha VK. Colon targeted gaur gm compression coated tablets of flrbiprofen: Formulation, development and pharmacokinetics. Bio Med Res Int. 2013; 2103: 1-8. Article ID 287919.

11. Wu B, Shun N, Wei X, Wu W. Characterization of 5-fluorouracil release from hydroxypropyl methylcellulose compression-coated tablets. Pharm Dev Tech. 2007; 12(2): 203-10.

12. Orlu M, Cevher E, Araman A. Design and evaluation of colonspecific drug delivery system containing flubiprofen microsponges. Int J Pharm. 2006; 318(1): 103-17.

13. Vemula SK, Veerareddy PR. Development, evaluation and pharmacokinetics of time-dependent ketorolac tromethamine tablets. Exp Opin Drug Del. 2013; 10(1): 33-45.

14. Demiroz FT, Acarturk F, Takka S, Boyunaga OK. In vitro and In vivo Evaluation of Mesalazine-Guar Gum Matrix Tablets for Colonic Drug Delivery. J Drug Targ. 2004; 12(2): 105-12.

15. Sinha VR, Singh A, Singh S. Compression coated systems for colonic delivery of 5-fluorouracil. J Pharm Pharmacol. 2007; 59(3): 359-65.
16. Chourasia MK, Jain SK. Pharmaceutical approaches to colon targeted drug delivery systems. J Pharm Pharmaceut Sci. 2003; 6(1): 33-66.

17. Shukla RK, Tiwari A. Carbohydrate polymers: Applications and recent advances in delivering drugs to the colon. Carb Polym. 2012; 88(2): 399-16.

18. Vemula SK, Veerareddy PR. Colon specific controlled release matrix tablets of flurbiprofen: formulation and characterization. Asian J Pharm Clin Res. 2012; 5(4): 92-6.

19. Vemula SK, Veerareddy PR. Fast disintegrating tablets of flurbiprofen: formulation and characterization. Lat Am J Pharm. $2011 ; 30(1): 1135-41$.

20. Vemula SK, Veerareddy PR, Devadasu VR. Pharmacokinetics of colon-specific $\mathrm{pH}$ and time-dependent flurbiprofen tablets. Eur $\mathrm{J}$ Drug Met Pharmacokinet. 2014; 1-11. DOI 10.1007/s13318-0140210-0.

21. Valluru R, Siddaramaiah T, Pramod M. Influence of natural polymer coating on novel colon targeting drug delivery system. J Mat Sci. 2008; 19(5): 2131-6.

22. Talukder RM, Fassihi R. Development and in vitro evaluation of a colon-specific controlled release drug delivery system. J Pharm Pharmacol. 2008; 60(10): 1297-03.

23. Chaudhary A, Tiwari N, Jain V, Singh R. Microporous bilayer osmotic tablet for colon-specific delivery. Eur J Pharm Biopharm. 2011; 78(1): 134-40.

24. ICH Q1A. Stability testing guidelines: Stability testing of new drug substances and products. CPMP//CH/380/95: 1-13.

25. Mathews BR. Regulatory aspects of stability testing in Europe. Drug Dev Ind Pharm. 1999; 25(7): 831-56.

26. Tugcu-Demiroz F, Acarturk F, Takka S, Konus-Boyunaga O. In vitro and in vivo evaluation of mesalazine-guar gum matrix tablets for colonic drug delivery. J Drug Targ. 2004; 12(2): 105-12.

27. Ashford M, Fell J, Attwood D, Woodhead P. An evaluation of pectin as a carrier for drug targeting to the colon. J Con Rel. 1993; 26(3): 213-20.

28. Sarasija S, Hota A. Colon-specific drug delivery systems. Ind J Pharm Sci. 2000; 62(1): 1-8.

29. Krishnaiah YSR, Satyanarayana S, Ramaprasad YV, Narasimharao $\mathrm{S}$. Evaluation of guar gum as a compression coat for drug targeting to colon. Int J Pharm. 1998; 171(2): 137-46.

30. Daravath B, Tadikonda RR, Vemula SK. Formulation and pharmacokinetics of gelucire solid dispersions of flurbiprofen. Drug Dev Ind Pharm. 2014; 1-19. DOI: 10.3109/03639045.2014.940963.

31. Vemula SK, Veerareddy PR, Devadasu VR. Pharmacokinetics of ketorolac tromethamine compression-coated tablets for colon delivery. Drug Del Trans Res. 2014; 4(4): 310-9.

32. Ghimire M, Hodges LA, Band J, Lindsay B, Mahony BO, Mclnnes FJ. Correlation between in vitro and in vivo erosion behavior of erodible tablets using gamma scintigraphy. Eur J Pharm Biopharm. $2011 ; 77(1): 148-57$. 